\title{
Valve in valve procedure and left main stent: To deliver or not to deliver
}

\author{
Ariana Gonzálvez-García, Harold Hernández-Matamoros, Alfonso Jurado-Román, \\ Guillermo Galeote, Santiago Jiménez-Valero, Raúl Moreno \\ Interventional Cardiology Unit, Cardiology Department, \\ La Paz University Hospital, Madrid, Spain
}

A 82-year-old woman was admitted for severe aortic regurgitation due to degenerated Mitroflow-21. Redo surgery was rejected and transcatheter valve-in-valve was planned.

There was a short distance from the bioprosthesis to the coronary ostia (Fig. 1A). Considering the risk of coronary obstruction, two undeployed drug-eluting stents were positioned at the left anterior descending and right coronary artery (Fig. 1B). Subsequently, a $23 \mathrm{~mm}$ Allegra bioprosthesis was implanted and since right coronary artery was patent, the gear was removed (Fig. 1C). Although there was no angiographic impairment of the left main, a guidewire deformation at the ostium was observed (Fig. 1D; asterisk). Moreover, the guiding catheter was non-deeply engaged and coaxial alignment was not viable. Due to the possibility of not retrieving the stent through the prosthesis and a likely delayed coronary obstruction, a stent at the left main was successfully deployed (Figs. 1E, F).

The present case highlights the importance of careful planning and the need for protecting coronary arteries with a guidewire, balloon or stent in valve-in-valve procedures to prevent coronary obstruction. However, it remains unknown which method is best. It is also controversial as to when stents should be deployed, since late vessel obstruction may occur. The difficulty of recovering the stent if the guiding catheter is not coaxial is another factor which should be kept in mind. For these reasons, if in doubt, a recommendation presented herein, is to deploy the stent to ensure coronary flow. Further investigation is required to know the best stent deployment technique: "chimney" versus "optimal ostial stent placement”.

Conflict of interest: Ariana Gonzálvez-García, Harold Hernández-Matamoros, Alfonso Jurado-Román, Guillermo Galeote and Santiago Jiménez-Valero declare no conflict of interest. Raúl Moreno is Allegra valve proctor for NVT.

Address for correspondence: Ariana Gonzálvez-García, MD, La Paz University Hospital, Paseo de la Castellana, 261, 28046, Madrid, Spain, tel: +34660199238, e-mail: arianagonzalvez@gmail.com

Received: 1.09.2019 Accepted: 30.11.2019 


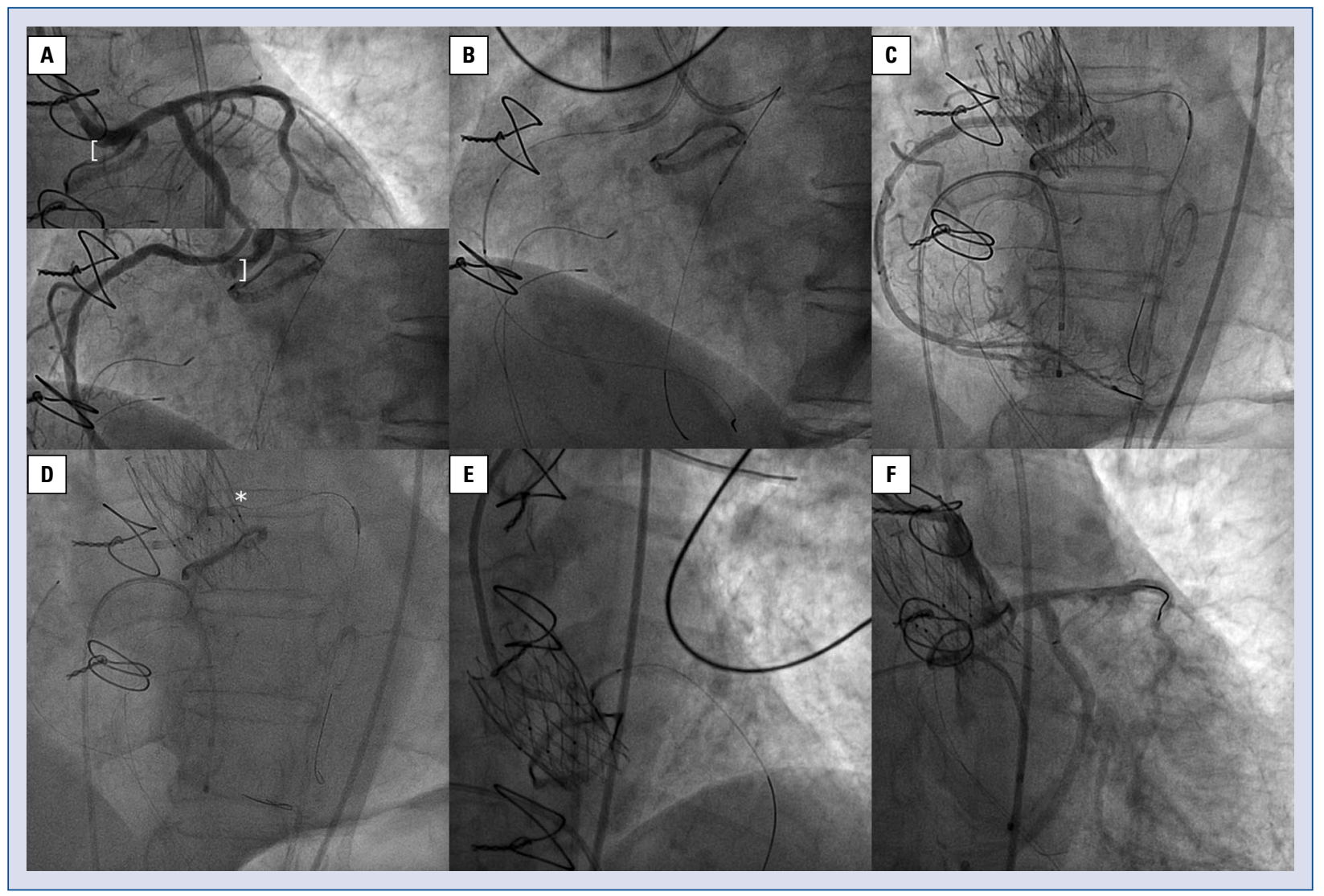

Figure 1. A. Distance between the bioprosthesis and coronary arteries; B. Undeployed stents at mid-left anterior descending and right coronary arteries; C. Patent right coronary artery after Allegra implantation; D. Asterisk: Deformed guidewire at ostial left main. Guiding catheter at the left main non-deeply engaged; E. Stent deployment in left main ostium; F. Patent left coronary tree. 